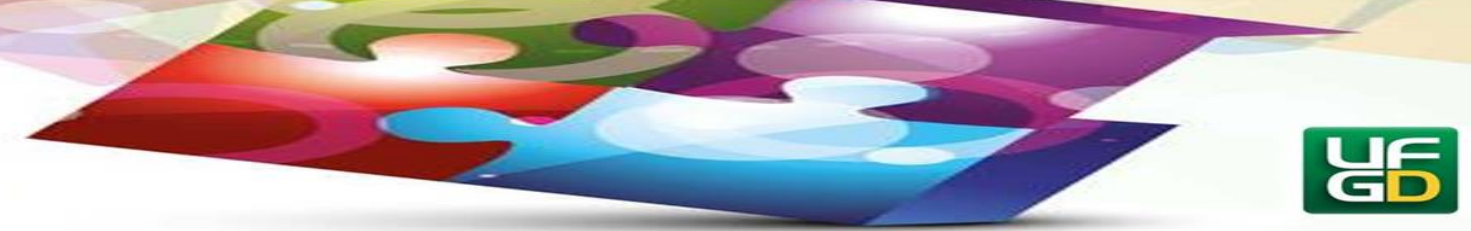

\title{
REFLEXões SOBRE A PRÁTICA PEDAGÓGICA DOS PROFESSORES POR MEIO DO ESPORTE
}

\section{REFLECTIONS ON THE PEDAGOGICAL PRACTICE OF TEACHERS THROUGH SPORTS}

Marcelo Jose TAQUES ${ }^{1}$ Silvia Christina de Oliveira MADRID ${ }^{2}$

\begin{abstract}
Resumo: este trabalho tem por objetivo apresentar um recorte da pesquisa realizada e concluída junto ao Programa de Pós Graduação Mestrado em Educação da UEPG/PR. O artigo apresenta como objetivo, evidenciar elementos básicos sobre o processo de intervenção desenvolvido pelos professores durante as aulas de Educação Física, nos anos finais do ensino fundamental. A pesquisa é qualitativa e com delineamento pautado na pesquisa de campo, utilizando como instrumento para a coleta de informações, a observação das aulas. Pretendemos nesse debate, contribuir com reflexões e possíveis ações para o ensino do esporte na escola a partir de uma perspectiva pedagógica, bem como valorizar o processo de pesquisa que possibilitem novos estudos à luz do desenvolvimento do esporte no contexto escolar.
\end{abstract}

Palavras-chave: Esporte na Escola. Estratégias de Ensino. Intervenção Docente.

Abstract: this paper aims to present a cut of the research carried out and concluded with the Postgraduate Program Master in Education of UEPG / PR. The article presents as objective, evidence basic elements about the intervention process developed by teachers during Physical Education classes, in the final years of elementary school. The research is qualitative and with a delineation based on field research, using as an instrument for the collection of information, the observation of classes. We intend in this debate to contribute with reflections and possible actions for the teaching of sports in the school from a pedagogical perspective, as well as to valorize the research process that make possible new studies in the light of the development of the sport in the school context.

Keywords: Sport at School. Teaching Strategies. Teacher Intervention.

\section{Introdução}

\footnotetext{
${ }^{1}$ Doutor em Educação pela Universidade Estadual de Ponta Grossa (UEPG). Atua como professor na Faculdade de Educação (FAED) da Universidade Federal da Grande Dourados (UFGD). E-mail: taques18@ yahoo.com.br ${ }^{2}$ Doutora em Ciência da Atividade Física e do Esporte Universidad de León da Espanha (UNILEON/ES), e Pós Doutora em Educação Física Universidade Federal de Santa Catarina (UFSC). Atua como docente no Curso de Licenciatura em Educação Física e no Programa de Pós-Graduação em Educação da UEPG. E-mail: silviamadrid@uol.com.br
} 


\section{HORIZONTES - REVISTA DE EDUCAÇÃO}

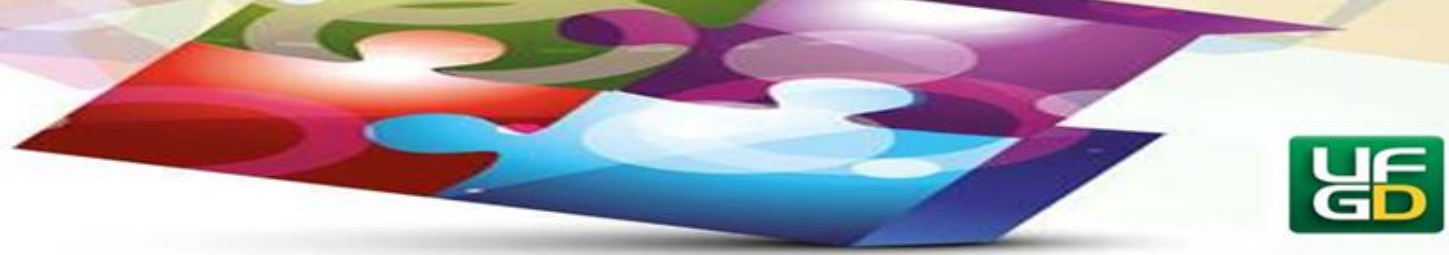

Os pressupostos deste artigo referem-se á um recorte dos estudos desenvolvidos no Programa de Pós-Graduação, Mestrado e Doutorado em Educação, da Universidade Estadual de Ponta Grossa (UEPG/PR).

Sabemos que o esporte atualmente vem sendo um dos temas mais abordados por pesquisadores, professores e estudantes, no intuito de trazer reflexões e ações sobre suas especificidades e formas intervenção em vários contextos na qual ele pode estar inserido, levando em consideração sua diversidade de manifestações e dimensões. Dessa forma, justificamos o fato de por meio dessa pesquisa, apresentar as características do esporte no contexto escolar a partir de duas realidades do município de Guarapuava - Pr.

Nesse sentido, cabe à luz de uma perspectiva crítica do esporte, analisar como o esporte pode ser desenvolvido por meio do seu valor educativo no contexto educacional de acordo com a realidade e as características dos alunos, deixando de considerar os parâmetros do esporte de alto rendimento como base, que tem entre seus princípios a seleção de talentos e a superação de recordes.

Nesse cenário, como pressuposto básico de nossa investigação, buscamos evidenciar por meio das categorias delimitadas, alguns elementos básicos sobre o processo de intervenção desenvolvido pelos professores durante as aulas de Educação Física, nos anos finais do ensino fundamental. Essas reflexões noz trazem subsídios necessários para repensarmos o trabalho com o esporte na escola e compreender os seus vários significados e sentidos que definem a sua característica polissêmica na sociedade.

\section{Método}

Este artigo se caracterizou como sendo uma pesquisa do tipo qualitativa, sendo que para chegarmos a essas discussões e reflexões, o delineamento desse estudo foi fundamentado na utilização de uma pesquisa de campo, utilizando como instrumento para a coleta de dados a observação de aulas de educação física $\operatorname{dos} 8^{\circ}$ e $9^{\circ}$ anos do ensino fundamental de duas instituições públicas de Guarapuava - Pr. As observações foram desenvolvidas semanalmente em duas (2) Escolas Públicas Estaduais (A, B) do Núcleo Regional do município de Guarapuava-PR, tendo como foco algumas questões relacionadas com o processo de intervenção pedagógica no processo de ensino do esporte nos $8^{\circ}$ e $9^{\circ}$ anos do ensino fundamental. 


\section{HORIZONTES - REVISTA DE EDUCACÃ̃O}

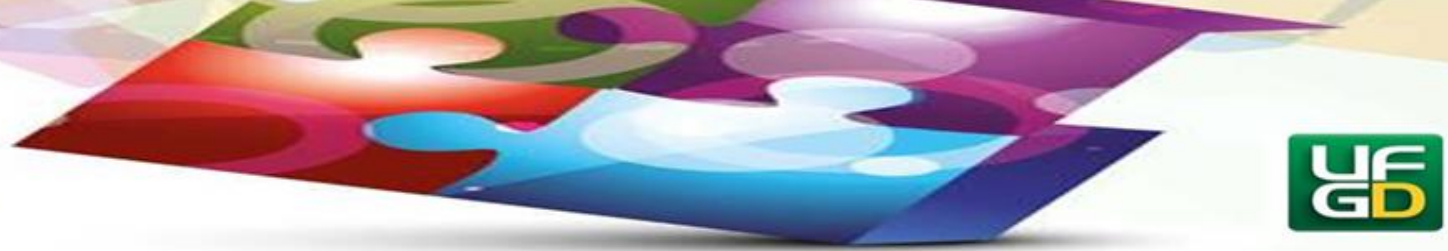

Os dados foram coletados por meio de uma ficha de observação elaborada de acordo com o instrumento utilizado por Finck (2005), sendo que para maiores especificações do campo de pesquisa, foi utilizado também um diário de campo para registrar de forma mais detalhada outros possíveis dados que também poderiam ser relevantes para a pesquisa, complementando dessa forma os registros da ficha de observação. Para abordar a intervenção dos professores, utilizamos a sigla professor 1, P1, professor 2, P2 e assim sucessivamente.

Vale ressaltar que todos os procedimentos éticos foram adotados, sendo apresentada uma carta de autorização para a direção das escolas e um termo de consentimento livre e esclarecido para os professores de Educação Física para a participação em pesquisa, sendo que esses instrumentos foram apresentados a Comissão de Ética em Pesquisa da instituição de ensino superior para análise e validação. Foi aprovado sob protocolo n ${ }^{\circ} 1.950 .694$.

Para promover a compreensão dos elementos que foram coletados a partir das observações realizadas, adotamos como técnica a Análise de Conteúdo (BARDIN, 1977), como critério para organização e categorização das informações identificadas na ficha de observação e no diário de campo, sendo a pesquisa delineada pelas seguintes categorias, as quais foram delimitadas a partir dos dados coletados por meio dos instrumentos utilizados:

a) A organização das aulas: conteúdo predominante e abordagem conceitual, procedimental e atitudinal;

b) Desenvolvimento do esporte nas aulas de Educação Física;

c) Ludicidade e/ou competição no ensino do esporte;

As discussões se deram em virtude do confronto entre as informações coletadas por meio das observações realizadas e das interpretações inferenciais desenvolvidas de acordo com as referências bibliográficas utilizadas sobre o referido tema.

Acreditamos que a temática desta pesquisa é relevante para a comunidade acadêmica da área, pois tem a intenção de ampliar as discussões e reflexões acerca da prática pedagógica desenvolvida pelos professores para ensino do esporte no contexto escolar, a fim de que possam colaborar para a cumulatividade e transferibilidade do conhecimento sobre esse conteúdo nas aulas de EF, a partir de uma perspectiva crítica e reflexiva. 


\section{Resultados}

\section{A organização das aulas: conteúdo predominante e abordagem conceitual, procedimental e atitudinal}

No que diz respeito aos aspectos relacionados à organização curricular da disciplina de EF, nas aulas são desenvolvidos conteúdos de acordo com uma abordagem (conceitual, procedimental e atitudinal), sendo assim, inicialmente torna-se necessário compreendermos de forma mais ampla sobre a definição dessas abordagens. A partir dos PCN (BRASIL, 1998, p. 51) primeiramente como abordagem conceitual entendemos que os conteúdos "referem-se à construção ativa das capacidades intelectuais para operar com símbolos, ideias, imagens e representações que permitem organizar a realidade. A aprendizagem de conceitos se dá por aproximações sucessivas".

Essa concepção atribuída aos conteúdos enfatiza uma aprendizagem que articula os conhecimentos previamente trazidos pelos alunos com as transformações ou novas leituras da realidade a partir do conteúdo que será proposto.

Tal aprendizado está totalmente articulado a segunda categoria denominada de procedimental, que segundo os PCN (BRASIL, 1998, p. 52), “expressam um saber fazer, que envolve tomar decisões e realizar uma série de ações, de forma ordenada e não aleatória para atingir uma meta". Essa categoria estabelece a participação que permite que se experimentem novas possibilidades e propostas de atividades que podem ser previamente elaboradas pelos professores e alunos no processo de ensino aprendizagem.

Para compor esse conjunto, temos a categoria dos conteúdos atitudinais "que permeiam todo o conhecimento escolar. A escola é um contexto socializador, gerador de atitudes relativas ao conhecimento, ao professor, aos colegas, às disciplinas, às tarefas e à sociedade" [...] "Ensinar e aprender atitudes requer um posicionamento claro e consciente sobre o que e como se ensina na escola" (BRASIL, 1998, p. 52-53).

Esse elenco de competências exigidas dos professores são partes integrantes da formação dos alunos, que durante o processo de ensino e aprendizagem somam novos saberes ou dão novas ressignificações àqueles que já possuem, a fim de atender as suas expectativas e/ou necessidades. 


\section{HORIZONTES - REVISTA DE EDUCAÇÃO}

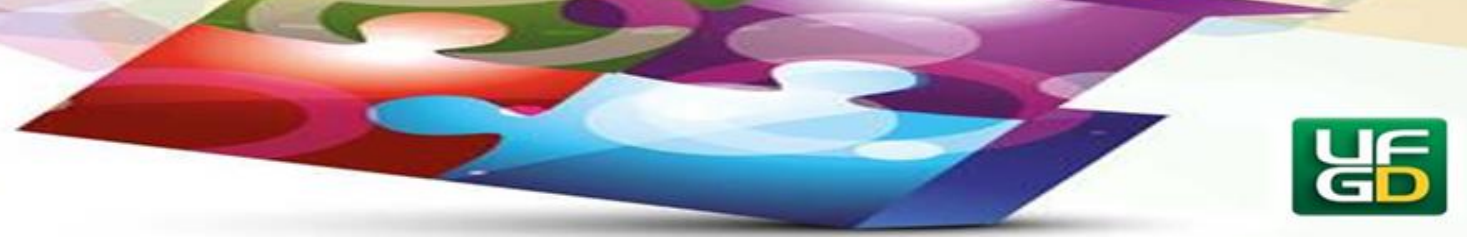

No universo da escola, podemos destacar que de acordo com uma perspectiva generalizada, as aulas de EF observadas seguem de alguma forma essas abordagens de conteúdos, no entanto, percebemos que em muitos momentos elas são efetivadas de forma fragmentada, nas quais o esporte é abordado no aspecto procedimental, ou seja, a proposta era que os alunos somente executassem as atividades sem uma abrangência mais complexa sobre o conteúdo que lhes possibilitasse a reflexão sobre o conhecimento ensinado.

Percebemos em muitos momentos que a forma proposta para os alunos participarem das aulas apresentava algumas características das relações hegemônicas que se apresentam explícitas no campo esportivo e na mídia e que acabavam sendo reproduzidas na escola, conforme estudos de Bourdieu (2002; 2003; 2004).

Cabe destacarmos nessa análise, que essa fragmentação na abordagem dos conteúdos pode ocasionar um conhecimento fragmentado, limitado e descontextualizado, pois as aulas nessa direção não seguem uma ordem sequencial durante o processo de intervenção. Como descreve Zabala (2002, p. 66), “o primeiro problema está relacionado à determinação dos conteúdos conceituais, procedimentais e atitudinais que promoverão a reconstrução e a ampliação dos conhecimentos preexistentes. O segundo problema está relacionado ao próprio processo de aprendizagem dos conteúdos". Corroborando com as ideias do autor, se os conteúdos não seguem uma sistematização e organização, dificilmente esses saberes inicialmente trazidos pelos alunos serão ampliados, eles acabam permanecendo no nível de superficialidade em relação aos conhecimentos.

Nessa linha de análise, percebemos que durante as aulas de EF da escola A no $8^{\circ}$ ano do ensino fundamental, o número médio de praticantes era vinte e nove (29) alunos e no $9^{\circ}$ ano, trinta e três (33) alunos, sendo que vários conteúdos eram abordados, como diversos tipos de jogos, brincadeiras, no entanto os conteúdos que predominavam durante as aulas foram "o voleibol, o futsal e principalmente o tênis de mesa, os quais eram desenvolvidos de forma teórica, com algumas explicações em sala de aula e por meio de aulas vivenciais sob a mediação do P1 ou sob a organização dos próprios alunos, definidas nessa pesquisa como aulas livres (AL)" (Diário de campo - Observação).

Sobre esses conteúdos predominantes, identificamos durante as observações que esses saberes também são proporcionados para os alunos em contraturno escolar em forma de escolinhas esportivas. Dessa forma, dentre os conteúdos citados acima, o tênis de mesa era o 


\section{HORIZONTES - REVISTA DE EDUCAÇÃO}

conteúdo do qual os alunos mais se apropriavam, pois de acordo com o diálogo com o P1A, “esse conteúdo é o que os alunos mais se identificam, devido ao amplo trabalho realizado em contraturno com esses alunos por meio de escolinha de tênis de mesa, que inclusive está entre as melhores escolas do Paraná nos Jogos escolares dessa modalidade" (Diário de campo Observação).

Acreditamos que essas considerações são relevantes, pois percebemos que os alunos são incentivados a participarem das práticas esportivas, inclusive em contraturno, contribuindo dessa forma para a inclusão dos alunos no esporte de participação, pois muitos por meio dessa abertura vivenciam essas modalidades em seus momentos de lazer, assim como no esporte de rendimento a partir de diversos jogos e campeonatos em que os alunos participam com excelentes resultados.

No entanto, identificamos inicialmente nas aulas de EF, que no desenvolvimento de alguns conhecimentos predominava a abordagem conceitual, que era efetivada somente em aulas consideradas teóricas, na qual o professor desenvolvia com auxílio de alguns recursos como a TV multimídia, algumas apresentações e explicações básicas sobre o histórico, dinâmica de jogo, identificação de elementos táticos e técnicos, entre outros, mas sem uma articulação com as atividades que eram desenvolvidas na prática (abordagem procedimental).

Essa configuração conseguimos perceber com maior clareza em uma aula na escola A, na qual o P1 tinha como objetivo "que os alunos reconhecessem as diferentes formas de realizar os fundamentos e principalmente o saque no voleibol, e como abordagem factual que eles buscassem uma compreensão a respeito da utilização dos diferentes fundamentos, destacando como exemplo, o saque" (Diário de campo - Observação).

Por meio dessa intervenção, alguns aspectos nos chamaram a atenção por mostrarem-se singulares, no sentido do P1 apresentar no início da aula o tema e os objetivos, e àquilo que foi proposto permanecer somente no contato inicial com os alunos, pois o tema da aula foi desenvolvido de forma desarticulada com o aspecto procedimental.

A intenção do P1 em desenvolver o conteúdo da aula de acordo com as abordagens conceitual e factual caracteriza-se como relevante, no entanto torna-se superficial, pois não recebe nenhuma proposta procedimental, alguma atividade que surpreenda o aluno ou que o estimule no desenvolvimento de sua criatividade para compreender esses fundamentos como disposições do esporte voleibol. 


\section{HORIZONTES - REVISTA DE EDUCAÇÃO}

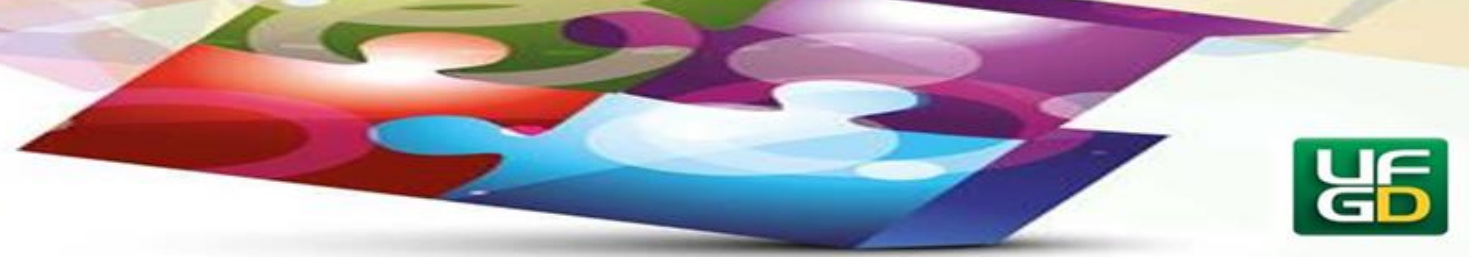

Entendemos que essas dimensões dos conteúdos, devem ser consideradas no processo de ensino aprendizagem de forma correlacionada, para que os saberes possam ser desenvolvidos de forma mais complexa de acordo com as necessidades e expectativas dos alunos, a fim de que eles possam refletir sobre o seu contexto, com condições de ampliar sua capacidade de critica e criatividade a partir de suas próprias análises durante o processo.

Para que seja possível potencializar o conhecimento dos alunos, segundo Zabala (2002, p. 62), “é necessário também ao docente primar para que novos conteúdos sejam cada vez mais significativos e dotados de conhecimento mais e mais profundo". Nessa linha de análise, é importante que as aulas sejam problematizadas e que incentivem os alunos pela busca de estratégias para a solução de seus desafios. Para isso, é necessário que os alunos tenham uma receptividade sobre o assunto a ser abordado, que eles possam vivenciar ou fazer as atividades a partir de uma abordagem procedimental e que essas experiências possam contribuir para o reconhecimento e valorização das aulas de EF para uma cultura esportiva por meio da construção de valores.

Portanto, de acordo com Macedo (2005, p. 61), “desenvolver competências e aprender a ensinar em um contexto de diversidade de pessoas e recursos tornou-se o grande desafio para os professores".

No que diz respeito às ações desenvolvidas na escola $\mathrm{B}$, o número médio de praticantes eram trinta e três (33) alunos tanto no $8^{\circ}$ quanto no $9^{\circ}$ ano, sendo que os conteúdos que apresentaram maior destaque de acordo com o planejamento do $\mathrm{P} 2 \mathrm{~B}$ foram o atletismo no $8^{\circ}$ ano e o basquetebol na turma de $9^{\circ}$ ano do ensino fundamental. A partir das situações observadas, em relação à distribuição da carga horária semanal da disciplina, percebemos a existência de uma forma de negociação entre professor e alunos sob o conteúdo a ser mediado. "Na aula foi estabelecido com os alunos como em outros conteúdos, que no atletismo, uma (01) aula seria teórica em "sala" para a discussão sobre o histórico, diferentes modalidades e seus fundamentos e as outras seriam práticas, para que na medida do possível os alunos pudessem vivenciar tais atividades" (Diário de campo - Observação).

Diante dessa configuração, acreditamos que esta seja uma estratégia docente para o processo de intervenção do conteúdo a ser ministrado, pois devido à aceitação e interesse dos alunos, inicialmente torna-se necessário criar meios para que a aprendizagem possa ser efetivada. No entanto, em relação às atitudes dos adolescentes durante a realização das 


\section{HORIZONTES - REVISTA DE EDUCAÇÃO}

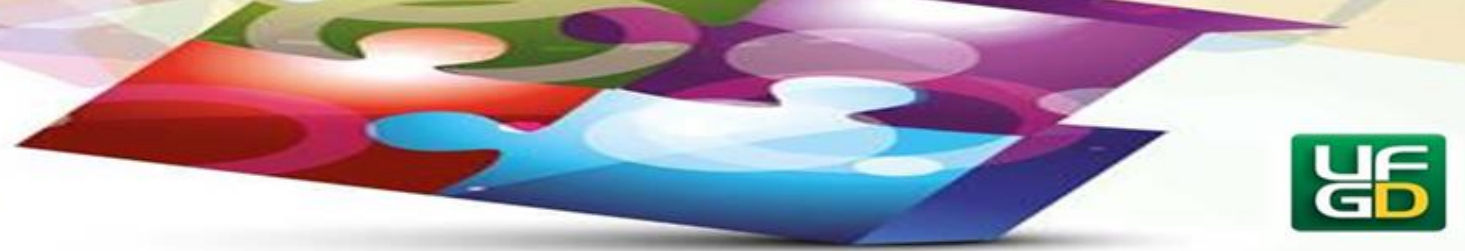

atividades, percebemos que "em alguns momentos existia resistência, em que alguns alunos questionavam o porquê das aulas de Educação Física ser teóricas, mas logo P2B mediava à situação explicando a importância e a necessidade dessas aulas para a formação dos mesmos" (Diário de campo - Observação).

Apesar de tais situações serem presenciadas, é importante frisarmos que a partir desse conteúdo as aulas seguiam uma coerência e uma ordem sequencial, sendo que conseguimos identificar que na maioria delas, os conteúdos eram abordados dentro das categorias conceituais, procedimentais e atitudinais. Um exemplo relevante foi que em uma das primeiras aulas, o P2 "estabeleceu inicialmente como abordagem conceitual que os alunos reconhecessem e classificassem as diversas modalidades do atletismo, identificando as capacidades físicas que eram necessárias para praticar essas modalidades" "que após seria cobrado em avaliação" (Diário de campo - Observação).

Nesse primeiro contato, o comportamento dos alunos foi interessante, pois até então nem todos conheciam as modalidades, mas que a partir das estratégias e explicações do professor essa prática social foi efetivada. De acordo com Pozo (1998, p. 32), "trata-se de um processo no qual o que aprendemos é o produto da informação nova interpretada à luz daquilo que sabemos".

No decorrer das aulas, após essas explicações os "alunos vivenciaram algumas dessas modalidades, classificando e diferenciando essas atividades e identificando as capacidades físicas necessárias em algumas provas de campo e de pista" (Diário de campo - Observação). Nesse momento, foi possível percebermos a motivação dos alunos na busca por esses conhecimentos, pois além do critério avaliativo que foi solicitado, os sujeitos estavam envolvidos na aula a partir das estratégias desenvolvidas pelo professor.

Essa situação de aprendizagem foi muito relevante, pois nos mostra que as metas começam a ser desenhadas, devido às necessidades que os alunos apresentam aos seus interesses e às relações que fazem com o saber de acordo com as suas realidades. Todo o encaminhamento articulado dessa forma pode como categoria atitudinal, fazer com que os alunos possam reconhecer e valorizar os conteúdos da Educação Física, fazendo com que esses saberes contribuam para a sua formação que vai além dos muros da escola, estabelecendo valores e virtudes que são resgatados por meio das práticas corporais historicamente 


\section{MORIZONTES - REVISTA DE EDUCAÇÃO}

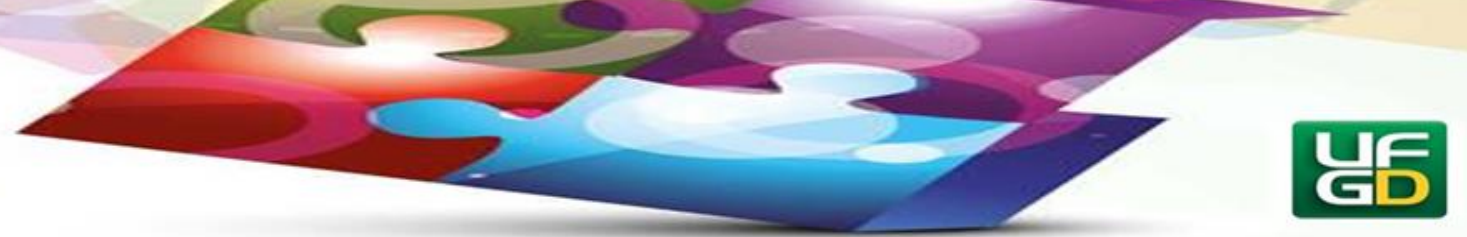

construídas, visando preparar cidadãos mais críticos e reflexivos em busca de melhores condições de vida.

Em relação à organização das aulas, por meio das observações na turma do $9^{\circ}$ ano do ensino fundamental, onde foi desenvolvido o conteúdo da modalidade esportiva basquetebol, foi possível identificarmos a presença do jogo como estratégia metodológica utilizada pelo P2 para a o ensino desse esporte na maioria das aulas. Esses aspectos nos mostram a relevância dos pressupostos teóricos sobre a pedagogia do esporte conforme estudos de Paes e Balbino (2001), Scaglia (1999; 2003), Freire (2003), Garganta e Graça (1995), Kroger e Roth (2002) e Greco e Benda (1998), para as novas possibilidades de ensinar o desporto no contexto da escola a partir de estratégias metodológicas diferenciadas em busca de um desenvolvimento multicultural do esporte de acordo com a realidade e as necessidades dos alunos.

Nessa linha de análise, nas primeiras aulas, "foram abordados alguns assuntos referentes ao conhecimento e a compreensão do contexto histórico do basquetebol, sendo utilizados como recursos a TV multimídia e vídeos sobre o assunto. Na sequencia das aulas o P2 começou a discutir e apresentar a parte técnica e tática do esporte, até chegar na categoria procedimental do conteúdo, possibilitando aos alunos algumas experiências práticas sobre o tema abordado por meio do jogo" (Diário de campo - Observação). Para melhor compreensão, podemos entender essa categoria procedimental, como "ações ou decisões que compõem a elaboração ou a participação", orientadas para a consecução de uma meta (COLL; VALLS, 1998, p. 77).

No decorrer da aula, conforme o repertório de atividades práticas que o P2 apresentava aos alunos de forma parcial, o referido professor explicava sobre a importância da tática e principalmente da técnica para a aprendizagem do basquetebol. A priori os "fundamentos eram apresentados por partes em pequenos grupos de acordo com a quantidade de materiais que estavam disponíveis. Em seguida, em vários momentos das aulas o P2 utilizava da metodologia do jogo para trabalhar esses fundamentos, proporcionando aos alunos jogos pré-desportivo que pudessem atender a maioria dos participantes de acordo com as suas limitações" (Diário de campo - Observação).

Nesse processo, utilizando o jogo como estratégia, foi solicitada aos alunos a execução de diferentes fundamentos de forma simultânea dentro do mesmo jogo, no intuito de fazer com que todos tivessem a oportunidade de vivenciar e cooperar na aula por meio de adaptações do 


\section{HORIZONTES - REVISTA DE EDUCAÇÃO}

espaço, nas regras e no tempo de jogo, que necessariamente não precisava ser de acordo com as exigências oficiais. Essas estratégias são relevantes e merecem destaque, já que conforme estudos de (BRACHT, 2009; FINCK, 2010; FREIRE, 2003), os elementos que compõe o esporte como, por exemplo, a técnica, é extremamente importante, no entanto, ela pode ser tratada por meio de diferentes perspectivas metodológicas não precisando necessariamente atender aos gestos técnicos padronizados que são exigidos no esporte performance.

Essas estratégias adotadas para o ensino do basquetebol a partir de uma perspectiva pedagógica são possibilidades de intervenção, no entanto vale ressaltar de acordo com NistaPiccolo e Moreira (2012, p. 70) que:

[...] não podemos deixar que os alunos sempre vivenciem adaptações do real. É importante levá-los a uma quadra oficial, permitindo que conheçam e experimentem aparelhos específicos da modalidade. Para isso, o professor deve mobilizar-se, buscando meios que o ajudem a atualizar toda a infraestrutura de sua escola.

Dessa forma, acreditamos que seja possível apreender sobre o esporte na escola por meio de diferentes perspectivas, porém, todas essas possibilidades devem ser submetidas à mobilização dos agentes para a sua efetivação e ressignificação no contexto escolar valorizando as necessidades e especificidades de cada um.

\section{Desenvolvimento do esporte nas aulas de Educação Física}

Frente à complexidade que envolve a prática pedagógica para o ensino do esporte na escola, por meio dessa categoria, nosso intuito foi apresentar como os conteúdos são desenvolvidos no processo de ensino aprendizagem a partir de algumas discussões que possam subsidiar a pesquisa sobre os tipos de aulas (fechadas ou abertas) e sobre as aproximações metodológicas que os professores utilizam para a mediação do conteúdo esporte no ensino fundamental em dois casos distintos.

Dentre as metodologias que se apresentam para a sistematização dos conteúdos na área da EFE buscamos na pesquisa à luz do referencial teórico que norteia a investigação, analisar como as aulas de EF são estruturadas e quais são os encaminhamentos metodológicos adotados pelos professores no processo de ensino aprendizagem. Dentre as abordagens estudadas, temos 


\section{MORIZONTES - REVISTA DE EDUCAÇÃO}

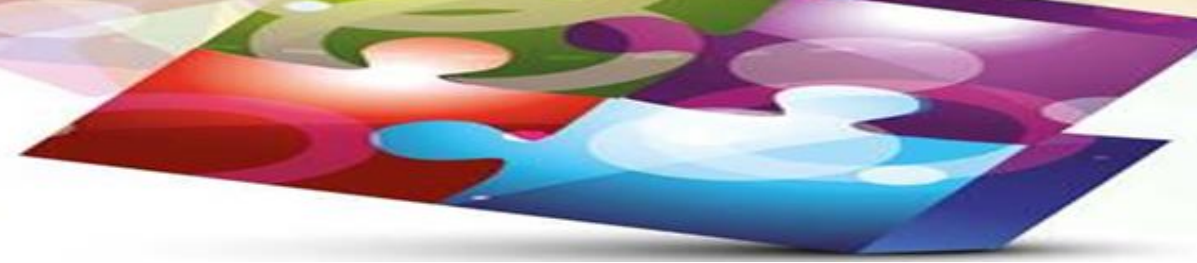

a concepção de ensino aberto (EA); sistêmica (S); crítico-superadora (CS); críticoemancipatória (CE); Parâmetros Curriculares Nacionais (PCNS); Diretrizes Curriculares da Educação Básica Educação Física (DCE); não identificada (NI); atividades livres (AL).

Quanto às abordagens/concepções da Educação Física, podemos observar que vários são os autores que discutem sobre elas, a fim de afirmar ou refutar a sua presença do contexto metodológico das aulas. Assim, com intuito de contribuirmos para as discussões sobre as abordagens da área da Educação Física escolar, buscamos por meio das observações, analisar como o conteúdo esporte é trabalhado e identificar de qual/quais estratégia (s) metodológica (s) essas intervenções se aproximam.

Sobre os tipos de aulas que eram desenvolvidas, percebemos por meio da ficha de observação que a partir das 44h/a que foram observadas no $8^{\circ}$ e $9^{\circ}$ anos, $32 \mathrm{~h} / \mathrm{a}$ se caracterizavam como aulas do tipo abertas (A), pois apesar de o professor não apresentar uma sequência dos conteúdos no que tange a organização conceitual, procedimental e atitudinal, as intervenções eram direcionadas aos alunos, para que as decisões não fossem tomadas somente pelo professor.

Referente à discussão sobre o encaminhamento metodológico que o P1A priorizava nas aulas, na maioria delas percebemos por meio das observações "que existia a defesa de um ensino que fosse centrado no aluno e que considerasse a sua experiência e seu interesse sobre o conteúdo" (Diário de campo - Observação).

Dessa forma, tanto no voleibol, no futsal, quanto no tênis de mesa que eram os conteúdos predominantes, o P1 seguia um processo metodológico estreitamente articulado ao ensino aberto (EA), que para uma melhor compreensão a partir das considerações de HildebrandtStramann (2005, p. 141-142), diferem a aula fechada da aula aberta salientando que "sob a Concepção de Aulas Fechadas podemos resumir as concepções de aulas orientadas: no professor, no produto; nas metas definidas e na intenção racionalista". E sob as aulas abertas "podemos resumir as concepções de aulas orientadas: no aluno, no processo na problematização e na comunicação".

Após a realização das 44 h/a de observações no $8^{\circ}$ e $9^{\circ}$ anos, constatamos na escola A, que a partir dos conteúdos predominantes na maioria das aulas, a metodologia destinada para seu desenvolvimento se aproximavam de três abordagens principais: ensino aberto (EA); sistêmica (S) e crítico-emancipatória (CE). 


\section{HORIZONTES - REVISTA DE EDUCAÇÃO}

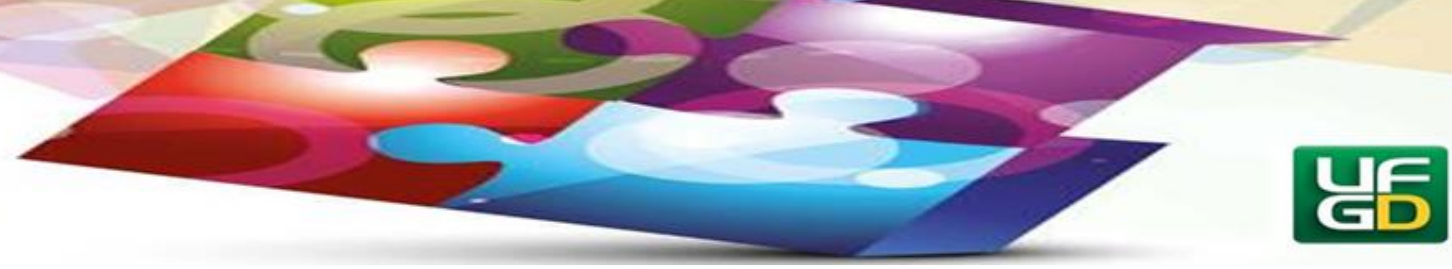

Primeiramente em relação à concepção do ensino aberto (EA), tal percepção surgiu por meio das "atitudes e formas com que o P1 tratava os conteúdos, desde a sua organização até a sua apresentação para os alunos, pois apesar de não observarmos uma ordem sequencial nas categorias conceituais, procedimentais e atitudinais, o P1 antes de qualquer processo de decisão, deixava uma abertura ou possibilidades de sugestões, questionamentos e de diálogo com os alunos, porém não utilizada por todos" (Diário de campo - Observação).

Percebemos essa aproximação a partir de um debate que o P1 desenvolveu em sala sobre o conteúdo futsal, no qual "apresentou um breve histórico sobre o conteúdo, suas regras e fundamentos básicos e após essas explicações deixou uma abertura para que os alunos falassem suas experiências com esse conteúdo, questionou de que forma era possível modificar as regras e trabalhar com os fundamentos do futsal sem excluir os colegas durante as aulas" (Diário de campo - Observação).

Essa ação comunicativa desenvolvida nessa aula buscou articular o aprender escolar com a vida e realidade dos alunos, fazendo com eles pudessem apresentar seus conhecimentos e mostrar sua criatividade a partir dos encaminhamentos sugeridos pelo professor. As aulas nessa perspectiva podem ser realizadas de diferentes maneiras, essa diferenciação depende do objetivo e do encaminhamento metodológico que o professor pretende desenvolver com seus alunos. Temos como exemplo a própria intervenção acima, na qual o P1 primeiramente solicita aos alunos que eles falem sobre suas experiências com o futsal e num segundo momento problematiza a aula, perguntando para os mesmos como as regras poderiam ser modificadas e como os fundamentos poderiam ser trabalhados a partir das características e limitações de cada um, sem que ninguém ficasse excluído da aula.

Por meio dessas análises acreditamos que as atitudes e ações do P1 tanto no $8^{\circ}$ quanto no $9^{\circ}$ ano do ensino fundamental se aproximam dessa abordagem, devido aos encaminhamentos metodológicos seguidos no processo de ensino e aprendizagem dos conteúdos propostos. Vale ressaltar que em algumas aulas, os alunos tinham a possibilidade de realizar as atividades livres (AL) de acordo com a sua escolha, no entanto, é relevante destacar que nesse processo não se caracteriza a presença da concepção de aulas abertas, pois assim como em outras teorias, essa abordagem segundo Lira Neto (2008, p. 65), "não nega a necessidade do planejamento, da escolha dos conteúdos e das intervenções do professor. Há diferentes graus sob os quais ocorre 


\section{HORIZONTES - REVISTA DE EDUCAÇÃO}

e-ISSN: 2318-1540

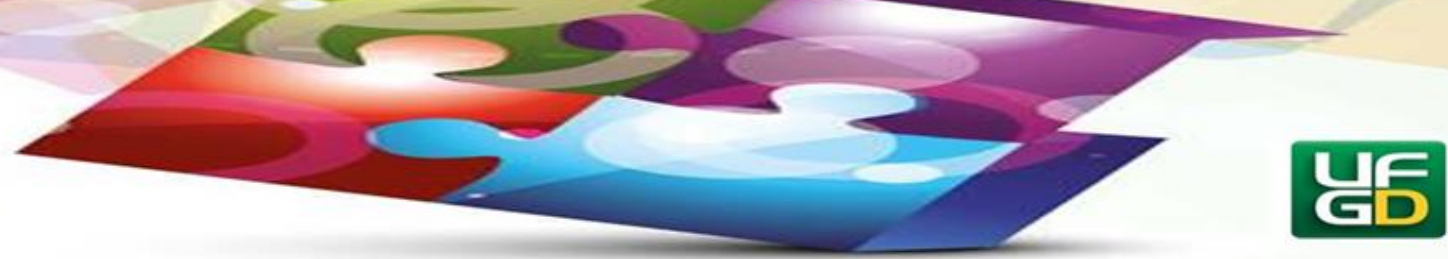

uma aula aberta, mas em nenhum deles os alunos são abandonados exclusivamente à sua livre iniciativa".

Em princípio podemos dizer que a concepção de aulas abertas não se configura como aulas livres (AL), pois a organização da aula depende do objetivo do professor de acordo com os conteúdos que serão escolhidos, da metodologia que será utilizada nas intervenções e dos critérios avaliativos que serão delimitados. Todos esses elementos compõem a sistematização de um planejamento que subsidie as ações docentes durante o trabalho com o ensino do esporte na escola a partir de uma perspectiva crítica.

Outra concepção de ensino que percebemos orientar os pressupostos e intervenções do P1A por meio do esporte no ensino fundamental foi a aproximação com a abordagem sistêmica (BETTI, 1991), a qual traz como proposta a integração do aluno no contexto da cultura corporal, valorizando princípios norteadores do processo de ensino durante as vivências e experimentações corporais.

Conforme as observações eram realizadas, "fomos percebendo uma relação da atuação do P1 com a metodologia em questão, essas características estavam presentes desde as aulas desenvolvidas em sala, assim como nas aulas "vivenciais" como se expressava P1" (Diário de campo - Observação).

Apesar das aulas nesses contextos muitas vezes não apresentarem sequência (conceitual, procedimental e atitudinal), demonstravam uma correlação com a abordagem sistêmica. Primeiramente, pela forma como o professor se expressava para proporcionar atividades práticas aos alunos, demonstrando um amplo interesse em fazer com que os alunos vivenciassem os conteúdos a partir das potencialidades e limitações que cada um apresentasse na modalidade.

Dentre os conteúdos desenvolvidos, o tênis de mesa foi o conteúdo no qual mais identificamos essas relações, pois apesar da escola proporcionar uma ampla intervenção com essa modalidade, inclusive em forma de escolinhas esportivas, muitos alunos ainda tinham dificuldade de praticar esse esporte. Nesse sentido, "O P1 diante dessas necessidades dos alunos, se posicionava argumentando sobre a importância de experimentar e vivenciar as atividades, para que a partir dos erros os alunos buscassem a sua superação" (Diário de campo - Observação). 


\section{HORIZONTES - REVISTA DE EDUCAÇÃO}

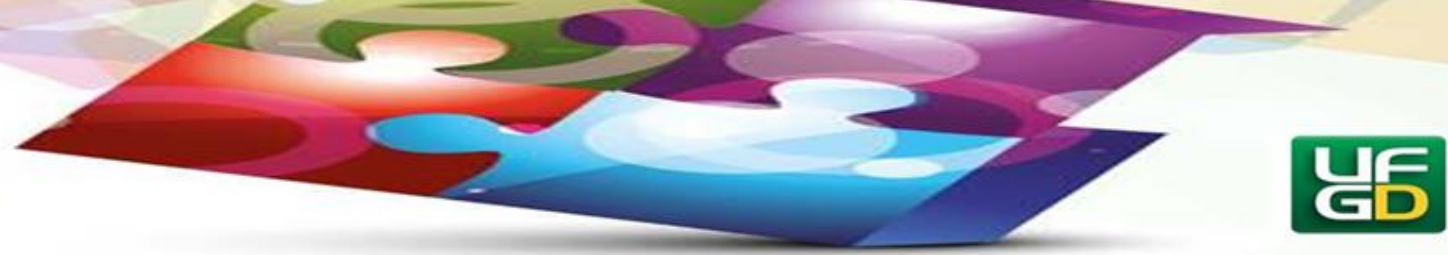

Entre essas considerações, notamos a importância de uma metodologia que seja condizente com as necessidades dos alunos, para isso, a intervenção do professor deve ser desenvolvida à luz de uma perspectiva crítica e criativa no sentido de estabelecer competências e habilidades para criar, diversificar e refletir sobre os conteúdos que serão ensinados.

Percebemos essas problematizações nas aulas várias vezes durante o trabalho do P1 com a modalidade do Tênis de mesa, "pois devido a dificuldade que alguns alunos ainda demonstravam com a modalidade, o P1 em vários momentos inseria atividades que envolviam o jogo para facilitar o trabalho com o conteúdo, principalmente com a parte técnica que esse modalidade individual exige" (Diário de campo - Observação).

Com base nessas estratégias utilizadas pelo P1 por meio do jogo, reforçamos a nossa compreensão sobre essa aproximação com a abordagem sistêmica, pois era notável o interesse do P1 em fazer com que todos os alunos participassem das aulas, assim como procurava diversificá-las por meio de várias atividades lúdicas relacionadas com o conteúdo esporte. Devido a esse processo, corroboramos com a ideia de Freire e Scaglia (2003, p. 31), quando ressaltam a importância das tarefas coletivas, e para isso, em se tratando de Educação Física, existem diversos recursos, dentre eles o privilégio de contar com os jogos, como simulações da vida social, como microuniversos de uma sociedade em crisálida.

Essa definição metodológica está estreitamente ligada aos princípios da não exclusão e da diversidade que são indispensáveis para que todos os alunos tenham as mesmas possibilidades de vivenciar e experimentar as atividades, identificando nessa intervenção, a relevância e a importância que essas práticas corporais atribuem a sua formação.

Outra aproximação metodológica que identificamos no campo de pesquisa para trabalhar com o esporte na escola é a abordagem crítico-emancipatória (KUNZ,1994). Essa abordagem se evidencia no contexto da escola "com a intenção de esclarecer as razões e as necessidades de introduzir, na escola, uma nova forma de tematizar o ensino, neste caso, o ensino do movimento, em especial, os esportes" (KUNZ, 2004, p. 13).

Com base nessas características, primeiramente um dos aspectos relevantes que observamos durante as aulas, "foi a estratégia didática do P1 na valorização do diálogo durante algumas aulas, a partir dos conteúdos que estavam sendo abordados, desde as ações comunicativas para que os alunos falassem sobre suas experiências, até os questionamentos 


\section{MORIZONTES - REVISTA DE EDUCAÇÃO}

realizados nas aulas para instrumentalizar os alunos para a reflexão e para a criação de estratégias que os conteúdos exigiam durante o processo" (Diário de campo - Observação).

A partir dessa constatação acreditamos que essas ações estão articuladas a essa abordagem, devido à abertura ao diálogo e as ações comunicativas desenvolvidas durante o processo de intervenção docente para o ensino do esporte.

Outras ações didáticas do P1 que se aproximam dessa abordagem, "foi a possibilidade de vivência dos conteúdos da forma que os alunos conheciam o esporte a partir de sua realidade. Tanto nas modalidades coletivas, quanto nas individuais, o P1 em uma parte da aula deixava que os alunos praticassem as atividades da forma como eles conheciam, sem a presença de técnicas especializadas e sem a presença de regras padronizadas, ao não ser as criadas pelos próprios alunos" (Diário de campo - Observação).

Esse encaminhamento está vinculado ao processo de transcendência de limites pela experimentação, que possibilita ao aluno o contato com o conteúdo a ser trabalhado a partir de suas próprias experiências com a modalidade. Conforme a aula era efetivada, algumas regras eram modificadas, sendo que essas transformações exigiam dos próprios alunos a necessidade de pensar em estratégias que pudessem contribuir para a solução dos desafios e problemas que eram inseridos durante as aulas, que de acordo com essa concepção se articula com a capacidade de criação desses sujeitos frente aos desafios enfrentados.

Referente às $42 \mathrm{~h} / \mathrm{a}$ que foram observadas na escola $\mathrm{B}$, tanto no $8^{\circ}$ quanto no $9^{\circ}$ ano do ensino fundamental, constatamos em $38 \mathrm{~h} / \mathrm{a}$ que o processo de ensino está vinculado a alguns pressupostos da abordagem do ensino aberto (EA) (HILDEBRANDT; LAGING, 1986), que valoriza e reconhece o conhecimento dos alunos de acordo com as suas experiências e limitações. No entanto, a articulação metodológica defendida pelo professor P2B na maioria das aulas observadas, estava relacionada a uma perspectiva crítica de educação, a qual se orienta a partir da abordagem crítico - superadora (CS) que é a base das DCE (PARANÁ, 2008). De acordo com os pressupostos de tal abordagem, segundo Resende e Soares (1997, p. 29), devemos selecionar os conteúdos clássicos necessários à formação do cidadão autônomo, crítico e participativo, para que este possa participar, intervir e comprometer-se com os rumos da sociedade possível, diante do momento histórico.

$\mathrm{Na}$ maioria das aulas, o professor $\mathrm{P} 2$ seguia a mesma sistematização referente ao conteúdo que era abordado. "No caso do basquetebol no $9^{\circ}$ ano, primeiramente buscava 


\section{HORIZONTES - REVISTA DE EDUCACÃ̃O}

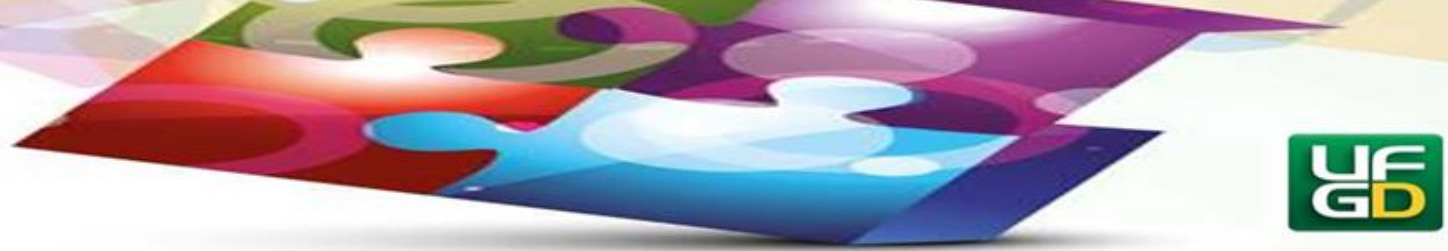

apresentar o conteúdo com o intuito de fazer uma leitura da realidade e uma análise do conhecimento e das experiências que os alunos possuíam sobre o assunto" (Diário de campo Observação).

Esse diálogo inicial com os alunos sobre o conteúdo proposto, no caso o basquetebol, é extremamente importante, pois gera no aluno confiança naquilo que vai fazer e ainda, possibilita um relacionamento agradável entre professor/aluno no processo de ensino aprendizagem. No mesmo sentido em que o professor P2 dialogava com os alunos, ele também "fazia provocações sobre a temática, questionando-os sobre a relação do esporte com a mídia, o porquê o basquetebol não é tão evidenciado e a diferença entre o esporte que os alunos assistem com o que eles praticavam na escola" (Diário de campo - Observação).

Diante dessas considerações, percebemos a importância dos professores planejarem suas aulas, a fim de efetivar uma organização do currículo que vá de encontro com a faixa etária e necessidades dos alunos, fazendo com que os saberes sejam definidos pelas áreas do conhecimento dos professores tendo sempre como fundamento básico de articulação, as necessidades sociais contemporâneas, que de acordo com intervenção observada, traz assuntos relevantes sobre a mídia e o mundo do trabalho.

Conforme o debate acontecia, as aulas prosseguiam com explicações sobre os questionamentos e sobre as regras e fundamentos básicos que eram necessários para a prática da modalidade. Esse momento é indispensável, pois se torna necessário que os alunos conheçam e adquiram o conhecimento científico dos assuntos que estão sendo abordados, pois se a escola permanecer somente com saber popular que os alunos trazem para a sala de aula, o ensino não precisa depender de objetivos, de metodologia adequada e de critérios avaliativos diversificados para ser efetivado. O fundamental é confrontar aluno e o professor com o conhecimento sistematizado, para que as ações didático-pedagógicas para a aprendizagem possam ser desenvolvidas a partir do que os alunos trazem à escola e aos poucos vai se ampliando de acordo com a mediação do professor.

Esse processo visa possibilitar aos alunos aspectos do conhecimento do seu cotidiano confrontando-os com o conhecimento científico, porém não de forma linear, mas do mais simples até chegar às intervenções mais complexas, as quais são desenvolvidas de forma espiralada e vão se ampliando (COLETIVO DE AUTORES, 1992). 


\section{HORIZONTES - REVISTA DE EDUCAÇÃO}

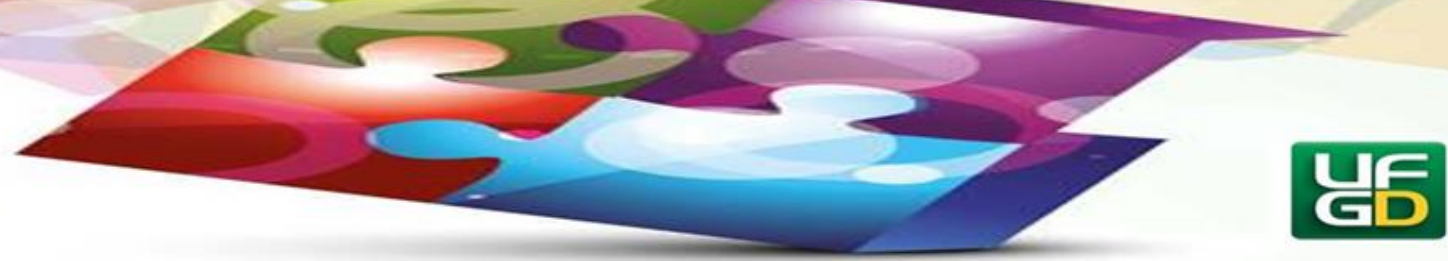

Nessa perspectiva referenciada, no decorrer do conjunto de aulas de EF sobre o basquetebol, foram proporcionadas práticas corporais sobre os assuntos abordados em sala (regras e fundamentos) tanto de forma parcial, quanto na utilização de grandes jogos prédesportivos da modalidade. Conforme as atividades eram desenvolvidas, o professor P2 em determinados momentos, inclusive como atividade avaliativa, "solicitava aos alunos que eles modificassem as regras do esporte para uma maior participação de quem tinha mais limitações, para que todos tivessem a posse de bola, etc., assim como solicitações para a recriação de jogos a partir daqueles que foram vivenciados para trabalhar a parte técnica e tática da modalidade" (Diário de campo - Observação).

Na perspectiva da reflexão sobre essas práticas corporais desenvolvidas, para verificar qual foi a modificação intelectual e qualitativa do professor e do aluno em relação as suas concepções iniciais sobre o conteúdo, após a realização das atividades sempre era realizada uma discussão a fim de identificar quais foram as dificuldades, as possibilidades, os pontos positivos e negativos e as sugestões dos alunos a respeito dos saberes abordados na aula.

Basicamente, esse momento é uma evolução da prática social inicial da aula, que traz como intenção identificar o crescimento e a transformação qualitativa que os sujeitos envolvidos no processo de ensino aprendizagem adquiriram durante as intervenções pedagógicas.

\section{Ludicidade e/ou competição no ensino do esporte}

Sabemos que os aspectos relacionados à ludicidade e a competição são temáticas causadoras de amplos debates no meio acadêmico da EF. Diante dessas discussões e de reflexões analíticas que efetivamos durante as observações, é que buscamos nesse momento contribuir para um processo de intervenção que valorize e reconheça o trabalho com os aspectos lúdicos e competitivos nas aulas de Educação Física, especificamente para o ensino do esporte.

Com base nessas considerações, notamos que a ludicidade é uma atividade espontânea com um fim em si mesmo e que contrapõe os valores da produtividade e da competitividade exacerbada. Diante dessas características, identificamos na escola A, no $8^{\circ}$ e no $9^{\circ}$ ano do ensino fundamental, que apesar de ser parte da aula com menor incidência, às atividades lúdicas 


\section{HORIZONTES - REVISTA DE EDUCAÇÃO}

estavam presentes, porém, "elas ficavam mais evidentes nas atividades de aquecimento que o P1 proporcionava aos seus alunos" (Diário de campo - Observação).

Essa informação é relevante, pois nos mostra a ausência de atividades que proporcionam a diversão e a espontaneidade nas aulas, sendo essa uma necessidade que carece ser superada diante do trabalho com os conteúdos da Educação Física na escola. A ludicidade deve ser vista como uma especificidade do momento e não como um veículo para alcançar outros objetivos como observamos em diversos momentos das aulas, em que "apesar de aparecer o jogo como metodologia para o ensino dos esportes, a ludicidade não era a questão predominante, pois existia nesse processo, a busca pelo desenvolvimento e aperfeiçoamento da técnica durante as atividades" (Diário de campo - Observação).

Vale ressaltarmos que existe a possibilidade de trabalhar várias questões por meio do jogo conforme nos apresentam Paes e Balbino (2005) em seus estudos sobre o jogo desportivo coletivo e as inteligências múltiplas, no entanto, não estamos fazendo uma crítica a esse processo de utilização do jogo como estratégia metodológica, porém, quando nos referimos ao termo da ludicidade, a presença de outros propósitos utilizando o jogo lúdico como meio, descaracteriza a espontaneidade e a atividade livre e criativa que esse conteúdo pode proporcionar.

Outro aspecto relevante que merece destaque nessas observações é o trabalho com a técnica nos esportes, pois, percebemos que ela vem sendo o motivo principal no desenvolvimento do esporte nas aulas de $\mathrm{EF}$ a partir de diversas estratégias metodológicas, no entanto, de acordo com Bracht, (2009); Bracht e Almeida (2003) e Vago (1996), sabemos que ela é importante para o trabalho com os esportes e nossa intenção não é de negação de sua relevância, porém, acreditamos que ela não deve ser a única preocupação do professor no trabalho com o esporte no contexto escolar.

No que diz respeito aos aspectos da ludicidade na escola $\mathrm{B}$, tanto no $8^{\circ}$ como no $9^{\circ}$ ano do ensino fundamental, observamos tanto no desenvolvimento do atletismo como de basquetebol, conforme já mencionado, a predominância $(\mathrm{P})$ da ludicidade por meio da ampla presença do jogo como subsídio para as ações do professor, a qual era efetivada de maneira oposta ao que foi observada no contexto anterior.

Devido à grande presença do jogo no contexto das aulas de EF da escola B, acreditamos que para uma maior compreensão, seja necessária a sua conceitualização. Nesse sentido, temos 


\section{HORIZONTES - REVISTA DE EDUCAÇÃO}

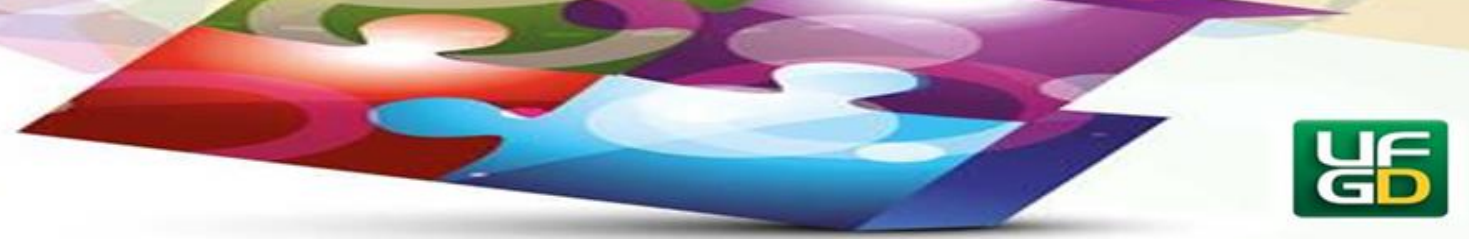

o posicionamento de Araújo (1992, p. 64), que conceitua o jogo como "uma atividade espontânea e desinteressada, admitindo uma regra livremente escolhida, que deve ser observada, ou um obstáculo deliberadamente estabelecido, que deve ser superado". Na escola B, por meio do jogo, "as aulas eram modificadas e a questão tática e tática foram alteradas no sentido de dar oportunidades aos alunos de "jogar" de forma espontânea e prazerosa, atendendo dessa forma, a maioria dos alunos que estavam participando das aulas" (Diário de campo Observação).

Sabemos que o lúdico pode ser desenvolvido de várias formas, no entanto, a partir dos contatos com o campo observado, presenciamos na maioria das aulas de EF, que as sistematizações que se evidenciavam por meio dos jogos pré-desportivos se destacavam e se aproximavam dos diversos pressupostos da pedagogia do esporte. Sendo assim, constatamos que por meio destas abordagens, o professor buscava além do trabalho com as questões típicas do esporte, abordar e estabelecer estratégias que pudessem resgatar alguns valores como dimensão atitudinal durante as atividades propostas.

Outro aspecto relevante que se faz salutar nessa pesquisa a partir da ficha de observações é a questão das intervenções pedagógicas com a questão da competição nos esportes, pois, por muito tempo, inclusive nos dias de hoje, muitas críticas são destinadas ao trabalho com a competição na escola, no entanto, a partir de análises e discussões sobre os estudos de Tubino (1992) e Kunz (2004), torna-se necessário desmistificar esses conceitos, no sentido de identificar que a competição não é o problema, mas sim a metodologia que muitas vezes pode estar sendo utilizada de forma equivocada no desenvolvimento do trabalho no contexto escolar.

Diante dessas considerações, buscamos durante as observações identificar como o esporte está sendo trabalhado nas escolas em relação à competição. Dessa forma, conforme o trabalho desenvolvido na escola $\mathrm{A}$, no $8^{\circ}$ e $9^{\circ}$ ano do ensino fundamental, identificamos que em 36h/a do total de observações realizadas nesse contexto, "a competição estava presente nas aulas, porém, ainda de forma predominante $(\mathrm{P})$ e exacerbada, inclusive dentro dos jogos em que a questão técnica era exigida com mais qualidade" (Diário de campo - Observação).

Essa percepção pode ter adquirido consequências das próprias intervenções durante as aulas, na qual as discussões sobre os valores e os diversos temas que estavam relacionados o esporte, eram tratados em sua superficialidade, somente a partir de conversas e conceitos. Nessa perspectiva, torna-se necessário buscarmos mais profundidade nas ações, a fim de pedagogizar 


\section{HORIZONTES - REVISTA DE EDUCAÇÃO}

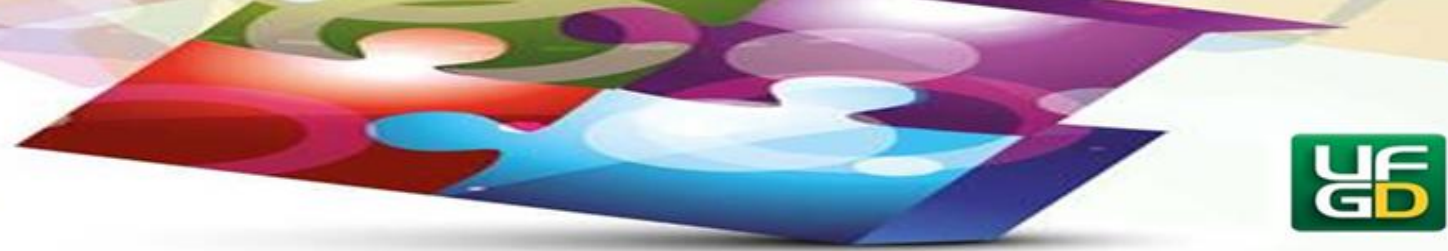

o esporte que será trabalhado dando mais ênfase no desenvolvimento das atitudes e da autonomia que podem ser efetivadas durante as vivências práticas e não somente nos diálogos ou reflexões sobre as propostas de intervenção.

Referente ao ensino do esporte no $8^{\circ}$ e $9^{\circ}$ ano do ensino fundamental da escola B sobre a questão da competição observamos em 28 h/a sua existência em algumas atividades (EA), pois a partir do processo de intervenção docente existia a valorização e o reconhecimento da relação entre a ludicidade e a competitividade no ensino dos esportes. Isso ficou evidenciado e todas as aulas que era proporcionado aos alunos durante o ensino dos conteúdos predominantes, os quais "seguiam uma sequência metodológica por meio do jogo, resgatando a diversão, a espontaneidade entre outros aspectos, mas que em outros momentos, sob outros critérios e objetivos, a competição aparecia como subsídio necessário para repensar os valores dos participantes e os desafios que cada um pudesse encontrar durante o seu convívio em sociedade" (Diário de campo - Observação).

Por meio dessas considerações, conseguimos compreender as diversas possibilidades de aprendizagem que o esporte pode oferecer, sendo a competição nesse processo, uma grande aliada para se atingir os objetivos considerados necessários para a formação dos alunos, pois “a ação pedagógica não envolve somente aspectos físicos e mecânicos do esporte, mas também deve transmitir valores sócio-culturais e projetar desafios que esses jovens poderão encontrar durante a sua vida" (BENELI; MONTAGNER, 2011, p. 33).

Diante dessas concepções, evidenciamos a importância de um planejamento docente, bem como uma metodologia que esteja articulada à realidade e a necessidades dos alunos, para que por meio do esporte, seja possível abordar valores, superar desafios e atingir objetivos que possam contribuir para o convívio social dos alunos.

\section{Considerações finais}

Com base nos pressupostos teóricos utilizados e nas decisões metodológicas de pesquisa, houve uma aproximação com o contexto da escola com o intuito de contribuirmos para esse debate em relação aos aspectos que envolvem as dimensões e manifestações do esporte, assim como os pressupostos teóricos e estratégias metodológicas que vem balizando 


\section{HORIZONTES - REVISTA DE EDUCAÇÃO}

e-ISSN: 2318-1540

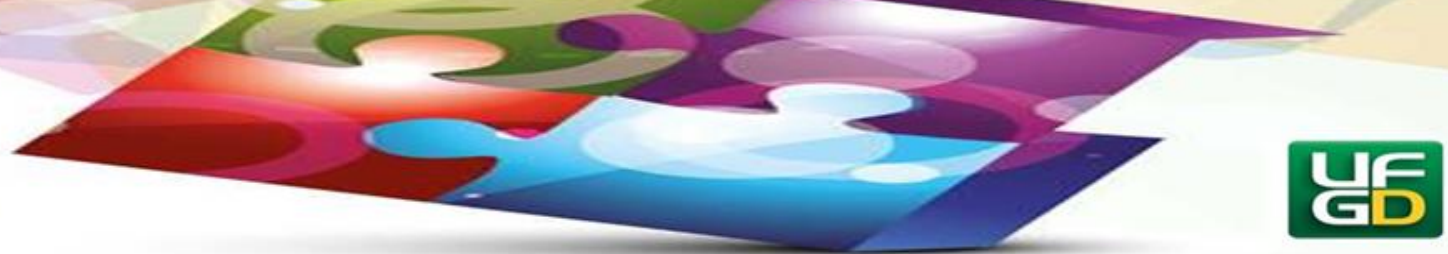

os encaminhamentos pedagógicos utilizados pelos professores de EF para o desenvolvimento do esporte.

Com base nestes resultados, acreditamos que o esporte, apesar de sua complexidade, pode ser ressignificado no contexto da escola para que se torne mais educativo diante das necessidades e expectativas dos alunos. Esperamos também, que essas análises possam permear novos estudos e provocar novas discussões no campo acadêmico e profissional da Educação Física sobre o ensino do esporte na escola e suas possibilidades de intervenção por parte dos professores de educação física.

Enfim, esperamos que esta pesquisa contribua para a construção de novos saberes sobre o processo de ensino e aprendizagem do esporte e para que novas discussões e debates sobre o fenômeno esportivo a partir de uma perspectiva polissêmica e multicultural, tanto no campo acadêmico, quanto no ambiente profissional possam ser desenvolvidas de forma sistematizada, inovadora e transformadora.

\section{Referências}

ARAÚJO, V. C. Aprender a brincar, aprender a viver. São Paulo: Manole, 1992.

BARDIN, L. Análise de Conteúdo. Lisboa: Edições 70, 1977.

BETTI, M. Educação Física e Sociedade, São Paulo: Movimento, 1991.

BENELI, L. M.; MONTAGNER, P. C. Intervenções pedagógicas na especialização esportiva de jovens atletas. In: MONTAGNER, P. C. Intervenções pedagógicas no esporte: práticas e experiências. São Paulo: Phorte, 2011.

BRACHT, V. Esporte de rendimento na escola. In: STIGGER, M. P.; LOVISOLO, H. Esporte de rendimento e esporte na escola. Campinas: Autores Associados, 2009.

BRACHT, V.; ALMEIDA, F. Q. A política de esporte escolar no Brasil: a pseudovalorização da Educação Física. In: Revista Brasileira de Ciências do Esporte, Campinas, v. 24, n. 3, 2003. p. 87-101.

COLETIVO DE AUTORES. Metodologia do ensino de Educação Física. São Paulo: Cortez, 1992.

FREIRE, J. B.; SCAGLIA, A. J. Educação como prática corporal. São Paulo: Scipione, 2003. 


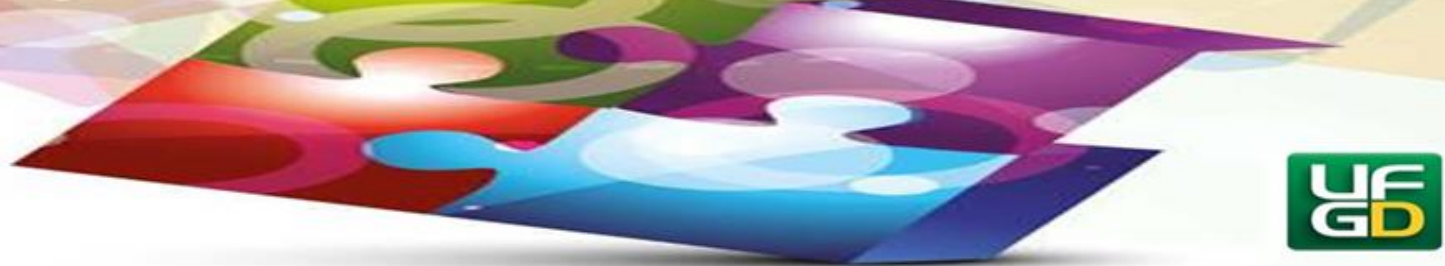

HILDEBRANDT, R.; LAGING, R. Concepções abertas no ensino da Educação Física. Rio de Janeiro: Ao livro Técnico, 1986.

HILDEBRANDT-STRAMANN, R. Textos pedagógicos sobre o ensino da Educação Física. 3. ed. Ijuí: Unijuí, 2005.

KUNZ, E. Transformação didático - pedagógica do esporte. Ijuí: Editora Unijuí, 1994.

. Transformação didático - pedagógica do esporte. 6. ed. Ijuí: Ed. Unijuí, 2004.

LIRA NETO, J. F. Relações entre a proposta das concepções abertas no ensino da educação física e o método Paulo Freire. Revista da Faculdade de Educação Física da UNICAMP, Campinas, v. 6, n. 2, p. 62-81, 2008.

PAES, R. R.; BALBINO, H. F; Pedagogia do Esporte: contextos e perspectivas. Rio de Janeiro: Guanabara Koogan, 2005.

PARANÁ. Secretaria de Estado da Educação. Departamento de Educação Básica. Diretrizes Curriculares da Educação Básica Educação Física. Curitiba: SEED/PR, 2008.

TUBINO, M. J. G. Uma visão paradigmática das perspectivas do esporte para o início do século XXI. In: GEBARA, A. et al. Educação Física e esportes perspectivas para o século XXI. Campinas: Papirus, 1992.

VAGO, T. M. O "esporte na escola" e o "esporte da escola": da negação radical para uma relação de tensão permanente - Um diálogo com Valter Bracht. Revista Movimento, vol III, Porto Alegre, ano 3, n. 5, p. 4-17, 1996.

Enviado: $30 / 07 / 2018$

Aceito: $19 / 10 / 2018$ 